\title{
REJECTION OF HARMONIC AND TRANSIENT DISTURBANCES OF A SMART STRUCTURE WITH PIEZOELECTRIC ACTUATORS
}

\begin{abstract}
SUMMARY
Light flexible structures are easily prone to vibrate due to external forces or due to forces generated in the inner structure. This situation is common in machinery or mechanical structures with rotational devices. The unwanted vibration of such structures can be compensated with the addition of piezoelectric actuators for active vibration control $(A V C)$. The rejection of harmonic disturbances is frequently done with controllers based on the internal model principle. The goal of this research is to reduce the effect of harmonic disturbances with known (measured) time-varying frequencies acting on a system as well as to increase the damping of the system for the transient response (first mode of vibration). The experimental setup is made up of a slender aluminium flexible beam, a pair of piezoelectric actuators, an accelerometer and two DC motors, as well as the data acquisition and signal conditioning equipment. The harmonic disturbance is generated by DC motors. The control design utilizes an augmented description of the plant. The plant including the disturbance is modelled as a polytopic linear parameter-varying ( $p L P V)$ system. An observer-based gain-scheduling controller is calculated based on quadratic stability and the stability is guaranteed for the specified range of variation of the scheduling parameters, also restriction in the performance is introduced in the sense of the $\mathrm{H}_{2}$-norm. Experimental results show very good disturbance cancellation.
\end{abstract}

Keywords: active vibration control, gain scheduling, linear parameter-varying systems, piezoelectric actuators

\begin{abstract}
STRESZCZENIE
Lekkie konstrukcje sa podatne na drgania wzbudzane przez wymuszenia zewnętrzne oraz sity występujace wewnątrz układu. Drgania tego typu konstrukcji moga być zredukowane przy zastosowaniu aktuatorów piezoelektrycznych i układów aktywnej regulacji. Układy eliminacji drgań często wykorzystują regulatory zaprojektowane przy wykorzystaniu modelu obiektu. Celem obecnych badań była redukcja wpływu harmonicznie zmiennych parametrów układu oraz zwiększenie tlumienia drgań nieustalonych. Obiekt sterowania został zamodelowany jako liniowy uktad niestacjonarny. Układ regulacji uwzględniajacy obserwator stanu zostat zaprojektowany przy wykorzystaniu normy $\mathrm{H}_{2}$. Przeprowadzono weryfikacje doświadczalna zaproponowanej metody. W skład stanowiska doświadczalnego wchodzity: podatna belka wykonana z aluminium, para aktuatorów piezoelektrycznych, akcelerometr, dwa silniki prądu stałego oraz układ akwizycji danych i ich kondycjonowania. Zaburzenie harmoniczne było generowane przez silniki pradu stałego. Wyniki badań doświadczalnych potwierdzily duża skuteczność zaproponowanej metody redukcji drgań.
\end{abstract}

Stowa kluczowe: aktywne thmienie drgań, harmonogramowanie wzmocnienia, liniowy układ niestacjonarny, aktuatory piezoelektryczne

\section{INTRODUCTION}

Light flexible structures are easily prone to vibrate due to external forces or forces generated in the inner structure. This situation is common in machinery or mechanical structures with rotational devices, due to imbalances, reciprocating mechanisms, etc. This effect can be attenuated by active vibration control (AVC). For lightweight flexible structures, piezoelectric materials are often used as actuators for AVC because they are light and can be easily integrated into structures without significantly changing the structural dynamics of the system (Kermani et al. 2008).

Usually the rejection of harmonic disturbances with time-varying frequencies is achieved through the imple- mentation of controllers which can be automatically adjusted to the disturbance frequencies. The classical approach used in AVC applications is adaptive filtering methods based on the Filtered-x Least Mean Square (FxLMS) algorithm (Kuo et al. 1996, Oh et al. 1998 and Shouwe et al. 2010). This approach was used by Oh et al. (1998) and Shouwe et al. (2010) to attenuate the effect of one harmonic disturbance acting on a flexible beam. The FxLMS approach often works well in practice but might suffer from disadvantages like slow convergence and poor tracking performance. For time-varying frequencies the analysis of such system is difficult because of its adaptive nature. Also, to the best authors' knowledge, only 'approximate stability results' are available for the FxLMS algorithm (Kuo et al. 1996).

\footnotetext{
* Institute of Electrical Information Technology, Clausthal University of Technology, Leibnizstr. 28, 38678 Clausthal-Zellerfeld, Germany; \{duarte,ballesteros,shu,bohn\}@iei.tu-clausthal.de
} 
The compensation of harmonic disturbances could be done with feedback controllers based on the internal model principle (Francis and Wonham 1976). These controllers have to include a model of the disturbance to achieve its rejection. Harmonic disturbances in many applications have time-varying frequencies. It means that to suppress these disturbances, the controller has to be adjusted to the frequency of the disturbance. It could be done by means of the observer-based state-feedback controllers, where disturbance observers are implemented for a plant augmented with a time-varying disturbance model and the observer gain is selected from a group of pre-computed gains (Bohn et al. 2003, 2004, Kinney and Callafon 2006). In this approach the stability is not guaranteed.

Another approach is the use of gain-scheduling techniques based on the system modelled as a linear parameter-varying (LPV) system. Dettori and Scherer (2001), Du et al. (2003), Ballesteros and Bohn (2011a, 2011b), Shu et al. (2011) and Duarte et al. $(2012,2013)$ employed gain-scheduling output-feedback controllers. In the work done by Heins et al. (2011, 2012a, 2012b) and Ballesteros et al. (2012) gain-scheduling observer-based controllers were implemented. In LPV models, the frequencies of the disturbances are assumed to vary in predefined ranges and their variations are approximated by a linear behaviour. In these works the modelling approach gives the possibility to obtain a parameter-independent Lyapunov function which ensures quadratic stability for the ranges of parameters variation. An important characteristic of these LPV controllers is that the scheduling parameters are calculated from the disturbance frequencies; therefore the controller can be adjusted in real time.

LPV techniques have not been extensively used in smart structures. In Onat et al. (2011) a gain-scheduling LPV controller was used for active control of a harmonic disturbance for a cantilevered flexible beam; however, the mass of a beam was the scheduling parameter and a harmonic disturbance with a constant frequency was considered. In Takagi and Saigo (2006) a smart beam with a crack is provided with a gain-scheduling LPV controller for the rejection of constant harmonic disturbances where the position and length of the crack were used as scheduling parameters.

The control design used in this work is based on Heins et al. (2011, 2012a, 2012b) and utilizes an augmented description of the plant. The plant combined with the disturbance is modelled as a polytopic linear parameter-varying (pLPV) system. An observer-based gain-scheduling controller is calculated based on quadratic stability and in the ranges of variation of the scheduling parameters the stability is guaranteed.

In this work the resulting controller is implemented in discrete time. In applications of active noise control (ANC) or AVC, the plant model is often obtained through system identification. This usually gives a discrete-time plant model. It is therefore most natural to carry out the whole design in discrete time.
The goal of this research is to reduce the effect of a harmonic disturbance with known (measured) time-varying frequencies acting on a system as well as to increase the damping of the system (first mode of vibration). The resulting controllers were tested on a slender flexible aluminium beam provided with a pair of piezoelectric actuators, an accelerometer and DC motors.

\section{CONTROL STRUCTURE FOR THE REJECTION OF HARMONIC DISTURBANCES WITH CONSTANT FREQUENCIES}

A linear time-invariant (LTI) plant has the state-space realization:

$$
\left[\begin{array}{c}
\boldsymbol{x}_{\mathrm{p}, k+1} \\
\hline y_{k}
\end{array}\right]=\left[\begin{array}{c|c}
\boldsymbol{A}_{\mathrm{p}} & \boldsymbol{B}_{\mathrm{p}} \\
\hline \boldsymbol{C}_{\mathrm{p}} & 0
\end{array}\right]\left[\begin{array}{c}
\boldsymbol{x}_{\mathrm{p}, k} \\
\hline u_{k}+y_{\mathrm{d}, k}
\end{array}\right],
$$

where $u_{k}$ is the control input and $y_{\mathrm{d}, k}$ is a harmonic disturbance acting on the plant input. The disturbance is modelled as the output of an unforced linear discrete-time system:

$$
\left[\begin{array}{c}
\boldsymbol{x}_{\mathrm{d}, k+1} \\
\hline y_{\mathrm{d}, k}
\end{array}\right]=\left[\begin{array}{c|c}
\boldsymbol{A}_{\mathrm{d}} & \mathbf{0} \\
\hline \boldsymbol{C}_{\mathrm{d}} & 0
\end{array}\right]\left[\begin{array}{c}
\boldsymbol{x}_{\mathrm{d}, k} \\
\hline 0
\end{array}\right] .
$$

This disturbance model is also referred to as exo-system. For a disturbance with $N$ constant frequencies a model is given by:

$$
\begin{aligned}
& \boldsymbol{A}_{\mathrm{d}}=\operatorname{diag}\left(\boldsymbol{A}_{\mathrm{d}_{i}}\right), i=1, \ldots, N, \\
& \boldsymbol{A}_{\mathrm{d}_{i}}=\left[\begin{array}{cc}
0 & 1 \\
-1 & 2 \theta_{i}
\end{array}\right], \\
& \theta_{i}=\cos \left(2 \pi f_{i} T\right), \\
& \boldsymbol{C}_{\mathrm{d}}=\left[\begin{array}{llll}
\boldsymbol{C}_{\mathrm{d}_{1}} & \boldsymbol{C}_{\mathrm{d}_{2}} & \cdots & \boldsymbol{C}_{\mathrm{d}_{N}}
\end{array}\right], \boldsymbol{C}_{\mathrm{d}_{i}}=\left[\begin{array}{ll}
1 & 0
\end{array}\right], i=1, \ldots, N,
\end{aligned}
$$

where $f_{i}$ is the frequency of the disturbance in $\mathrm{Hz}$ and $T$ is the sampling time. A controller for the rejection of a disturbance must contain the model of the disturbance. This is known as the internal model principle (Francis and Wonham 1976). The controller poles are defined through the poles of the disturbance model (only valid for the case of constant frequencies), which are zeros of the closed loop (assuming there is no pole-zero cancellation between the disturbance and the plant). This leads to a controller with a high gain for the frequencies to be rejected. The resulting controller is capable to reject the harmonic disturbances no matter where they are located in the system.

The calculation of a controller based on the internal model principle can be done in different ways; here an observer-based controller of the overall system is obtained using a combination of plant and disturbance (see fig. 1). 


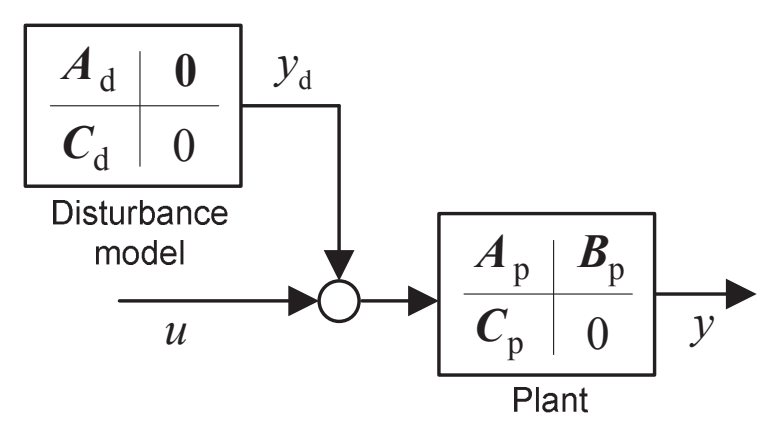

Fig. 1. Overall LTI system

A state-space representation of the overall system is given as:

$$
\begin{aligned}
& {\left[\begin{array}{l}
\boldsymbol{x}_{k+1} \\
\hline y_{k}
\end{array}\right]=\left[\begin{array}{l|l}
\boldsymbol{A} & \boldsymbol{B} \\
\hline \boldsymbol{C} & 0
\end{array}\right]\left[\begin{array}{l}
\boldsymbol{x}_{k} \\
\hline u_{k}
\end{array}\right],} \\
& \boldsymbol{x}_{k}=\left[\begin{array}{c}
\boldsymbol{x}_{\mathrm{p}, k} \\
\boldsymbol{x}_{\mathrm{d}, k}
\end{array}\right], \boldsymbol{A}=\left[\begin{array}{cc}
\boldsymbol{A}_{\mathrm{p}} & \boldsymbol{B}_{\mathrm{p}} \boldsymbol{C}_{\mathrm{d}} \\
\mathbf{0} & \boldsymbol{A}_{\mathrm{d}}
\end{array}\right], \boldsymbol{B}=\left[\begin{array}{c}
\boldsymbol{B}_{\mathrm{p}} \\
\mathbf{0}
\end{array}\right], \boldsymbol{C}=\left[\begin{array}{ll}
\boldsymbol{C}_{\mathrm{p}} & \mathbf{0}
\end{array}\right] .
\end{aligned}
$$

An identity observer:

$$
\hat{\boldsymbol{x}}_{k+1}=(\boldsymbol{A}-\boldsymbol{L} \boldsymbol{C}) \hat{\boldsymbol{x}}_{k}+\boldsymbol{B} u_{k}+\boldsymbol{L} y_{k}
$$

is employed to estimate the states of the overall system (7).

The estimated states are then used in the state-feedback law:

$$
u_{k}=-\boldsymbol{K} \hat{\boldsymbol{x}}_{k}=-\left[\begin{array}{ll}
\boldsymbol{K}_{\mathrm{p}} & \boldsymbol{K}_{\mathrm{d}}
\end{array}\right] \hat{\boldsymbol{x}}_{k} .
$$

The time-invariant feedback gain $\boldsymbol{K}$ is composed of a feedback gain $\boldsymbol{K}_{\mathrm{p}}$ for the estimated plant states $\hat{\boldsymbol{x}}_{\mathrm{p}}$ and a feedback gain $\boldsymbol{K}_{\mathrm{d}}$ for the estimated disturbance states $\hat{\boldsymbol{x}}_{\mathrm{d}}$. The combination of observer and feedback controller gives an observer-based controller described by:

$$
\left[\begin{array}{c|c}
\boldsymbol{x}_{\mathrm{c}, k+1} \\
\hline u_{k}
\end{array}\right]=\left[\begin{array}{c|c}
(\boldsymbol{A}-\boldsymbol{L} \boldsymbol{C}-\boldsymbol{B} \boldsymbol{K}) & \boldsymbol{L} \\
\hline-\boldsymbol{K} & 0
\end{array}\right]\left[\begin{array}{c}
\boldsymbol{x}_{\mathrm{c}, k} \\
y_{k}
\end{array}\right] .
$$

With the introduction of the observer error $\tilde{\boldsymbol{x}}=\boldsymbol{x}-\hat{\boldsymbol{x}}$ the closed-loop dynamics can be written as:

$$
\left[\begin{array}{c}
\boldsymbol{x}_{\mathrm{p}, k+1} \\
\tilde{\boldsymbol{x}}_{k+1} \\
\boldsymbol{x}_{\mathrm{d}, k+1}
\end{array}\right]=\left[\begin{array}{ccc}
\boldsymbol{A}_{\mathrm{p}}-\boldsymbol{B}_{\mathrm{p}} \boldsymbol{K}_{\mathrm{p}} & \boldsymbol{B}_{\mathrm{p}} \boldsymbol{K} & \boldsymbol{B}_{\mathrm{p}}\left(\boldsymbol{C}_{\mathrm{d}}-\boldsymbol{K}_{\mathrm{d}}\right) \\
\mathbf{0} & \boldsymbol{A}-\boldsymbol{L} \boldsymbol{C} & \mathbf{0} \\
\mathbf{0} & \mathbf{0} & \boldsymbol{A}_{\mathrm{d}}
\end{array}\right]\left[\begin{array}{c}
\boldsymbol{x}_{\mathrm{p}, k} \\
\tilde{\boldsymbol{x}}_{k} \\
\boldsymbol{x}_{\mathrm{d}, k}
\end{array}\right] .
$$

A suitable calculation of $\boldsymbol{L}$ and $\boldsymbol{K}$ leads to a stable controller and asymptotically stable observer error $\tilde{\boldsymbol{x}}$.

\section{CONTROL DESIGN FOR PLPV SYSTEMS}

In many industrial applications, harmonic disturbances are time-varying, for this reason here a method to calculate a gain-scheduling controller for multiple time-varying disturbances is presented. This method is proposed in Heins et al. $(2012 \mathrm{a}, 2012 \mathrm{~b})$ for the rejection of harmonic distur- bances. This control design has the same structure as the LTI case and here is extended to the LPV case. Considering a system perturbed with $N$ time-varying frequencies modelled with a polytopic approach, $M$ LTI systems (vertex systems) are defined for all the possible combinations of the extreme values for the frequencies of each disturbance.

\subsection{Observer-based state-feedback controller for the rejection of time-varying disturbances}

The LTI plant presented in (1) is augmented with a time-varying disturbance model described by:

$$
\left[\begin{array}{c}
\boldsymbol{x}_{\mathrm{d}, k+1} \\
\hline y_{\mathrm{d}, k}
\end{array}\right]=\left[\begin{array}{c|c}
\boldsymbol{A}_{\mathrm{d}, k} & \mathbf{0} \\
\hline \boldsymbol{C}_{\mathrm{d}} & 0
\end{array}\right]\left[\begin{array}{c}
\boldsymbol{x}_{\mathrm{d}, k} \\
\hline 0
\end{array}\right] .
$$

With the inclusion of this time-varying disturbance, the overall time-varying system:

$$
\left[\begin{array}{c}
\boldsymbol{x}_{k+1} \\
\hline y_{k}
\end{array}\right]=\left[\begin{array}{c|c}
\boldsymbol{A}_{k} & \boldsymbol{B} \\
\hline \boldsymbol{C} & 0
\end{array}\right]\left[\begin{array}{c}
\boldsymbol{x}_{k} \\
u_{k}
\end{array}\right],
$$

is obtained with

$$
\begin{gathered}
\boldsymbol{x}_{k}=\left[\begin{array}{c}
\boldsymbol{x}_{\mathrm{p}, k} \\
\boldsymbol{x}_{\mathrm{d}, k}
\end{array}\right], \boldsymbol{A}_{k}=\left[\begin{array}{cc}
\boldsymbol{A}_{\mathrm{p}} & \boldsymbol{B}_{\mathrm{p}} \boldsymbol{C}_{\mathrm{d}} \\
\mathbf{0} & \boldsymbol{A}_{\mathrm{d}, k}
\end{array}\right], \boldsymbol{B}=\left[\begin{array}{c}
\boldsymbol{B}_{\mathrm{p}} \\
\mathbf{0}
\end{array}\right], \\
\boldsymbol{C}=\left[\begin{array}{ll}
\boldsymbol{C}_{\mathrm{p}} & \mathbf{0}
\end{array}\right] .
\end{gathered}
$$

A time-varying identity observer:

$$
\hat{\boldsymbol{x}}_{k+1}=\left(\boldsymbol{A}_{k}-\boldsymbol{L}_{k} \boldsymbol{C}\right) \hat{\boldsymbol{x}}_{k}+\boldsymbol{B} u_{k}+\boldsymbol{L}_{k} y_{k}
$$

with a time-varying observer gain $\boldsymbol{L}_{k}$ is used to estimate the states of the augmented plant.

The state-feedback gain $\boldsymbol{K}$ is introduced to generate the control signal with the estimated states of the plant and the states of the disturbances. Provided that the state-feedback gain is time invariant, the same feedback law:

$$
u_{k}=-\boldsymbol{K} \hat{\boldsymbol{x}}_{k}=-\left[\begin{array}{ll}
\boldsymbol{K}_{\mathrm{p}} & \boldsymbol{K}_{\mathrm{d}}
\end{array}\right] \hat{\boldsymbol{x}}_{k}
$$

used for the LTI case can be applied for time-varying frequencies. The state-feedback gain for the plant states $\boldsymbol{K}_{\mathrm{p}}$ can be calculated, using pole placement or linear quadratic regulator (LQR) techniques, to stabilize the plant and to damp its resonance frequencies. The choice of $\boldsymbol{K}_{\mathrm{d}}$ has no effect on the overall system stability (as long as $\boldsymbol{K}_{\mathrm{d}} \hat{\boldsymbol{x}}_{\mathrm{d}}$ remains bounded). Furthermore, it can be seen that, assuming a perfect disturbance model, complete asymptotic disturbance cancellation will be achieved if $\boldsymbol{K}_{\mathrm{d}}=\boldsymbol{C}_{\mathrm{d}}$.

\subsection{Gain-scheduled observer design for $p L P V$ systems}

The time-varying observer gain $\boldsymbol{L}_{k}$ required for the approach introduced in the previous section is obtained by interpolation of fixed pre-computed observer gains of vertex systems of the overall system (14), which is modelled as a pLPV 
system (see also Stilwell and Rugh 1998, Daafouz et al. 2000). The aim is to obtain an asymptotically stable observer. Quadratic stability theory of pLPV systems is therefore used and is briefly presented in this section. An autonomous pLPV system has the form:

$$
\boldsymbol{x}_{k+1}=\boldsymbol{A}(\boldsymbol{\theta}) \boldsymbol{x}_{k}
$$

where the system matrix depends affinely on the parameter vector $\boldsymbol{\theta}$ as:

$$
\boldsymbol{A}(\boldsymbol{\theta})=\mathcal{A}_{0}+\theta_{1} \mathcal{A}_{1}+\ldots+\theta_{N} \mathcal{A}_{N}
$$

for constant matrices $\mathcal{A}_{i}$. The parameter vector $\theta$ varies in a polytope $\Theta$ with $M$ vertices $\boldsymbol{v}_{j} \in \mathbf{R}^{N}$. A point $\theta \in \Theta$ can be written as a convex combination of vertices, i.e. there exist coordinates $\lambda=\left[\begin{array}{lll}\lambda_{1} & \cdots & \lambda_{M}\end{array}\right]^{\mathrm{T}} \in \mathbf{R}^{M}$ with:

$$
\lambda_{j} \geq 0, \sum_{j=1}^{M} \lambda_{j}=1 \text { and } \theta=\sum_{j=1}^{M} \lambda_{j} \boldsymbol{v}_{j} .
$$

With $\boldsymbol{A}_{\mathrm{v}, j}=\boldsymbol{A}\left(\boldsymbol{v}_{j}\right)$ for $j=1, \ldots, M$ it then holds that:

$$
A_{k}=A(\theta)=A(\lambda)=\lambda_{1} A_{\mathrm{v}, 1}+\lambda_{2} A_{\mathrm{v}, 2}+\ldots+\lambda_{M} A_{\mathrm{v}, M} .
$$

The pLPV-system (17) is called quadratically stable if and only if there exists a matrix $\boldsymbol{P}=\boldsymbol{P}^{\mathrm{T}}>0$ such that $\boldsymbol{A}^{\mathrm{T}}(\boldsymbol{\theta}) \boldsymbol{P} \boldsymbol{A}(\boldsymbol{\theta})-\boldsymbol{P}<0$ for all $\boldsymbol{\theta} \in \Theta$. Via the Schur complement, this can also be stated as:

$$
\left[\begin{array}{cc}
\boldsymbol{P} & \boldsymbol{P} A(\theta) \\
A(\theta)^{\mathrm{T}} \boldsymbol{P} & \boldsymbol{P}
\end{array}\right]>0 \text { for all } \boldsymbol{\theta} \in \Theta .
$$

This infinite set of LMIs can be replaced by a finite set. It holds that the system, defined by $\boldsymbol{x}_{k+1}=\boldsymbol{A}(\boldsymbol{\theta}) \boldsymbol{x}_{k}$ is quadratically stable for every $\theta \in \Theta$ if and only if there exists a matrix $\boldsymbol{P}=\boldsymbol{P}^{\mathrm{T}}>0$ such that:

$$
\boldsymbol{A}_{\mathrm{v}, j}^{\mathrm{T}} \boldsymbol{P} \boldsymbol{A}_{\mathrm{v}, j}-\boldsymbol{P}<0 \text { for all } j=1, \ldots, M .
$$

where $\boldsymbol{A}_{\mathrm{v}, j}$ are the overall vertex system matrices. This result is based on one common quadratic Lyapunov function that is independent of the parameter vector $\theta$. Therefore, $\theta$ is allowed to change arbitrarily fast with time and $\theta$ and $\lambda$ can explicitly be denoted as $\theta_{k}$ and $\lambda_{k}$, respectively. A proof is found in Amato (2006).

Applying this to the design of the observers required for the approach introduced in the previous section, it results that it suffices to find a matrix $\boldsymbol{P}=\boldsymbol{P}^{\mathrm{T}}>0$ and a finite set of matrices $\boldsymbol{L}_{\mathrm{v}, j}$ such that $\left(\boldsymbol{A}_{\mathrm{v}, j}-\boldsymbol{L}_{\mathrm{v}, j} \boldsymbol{C}\right)^{\mathrm{T}} \boldsymbol{P}\left(\boldsymbol{A}_{\mathrm{v}, j}-\boldsymbol{L}_{\mathrm{v}, j} \boldsymbol{C}\right)-\boldsymbol{P}<0$ for all $j=1, \ldots, M$ to guarantee quadratic stability, which implies uniform asymptotic stability for the whole parameter space. The current observer gain $\boldsymbol{L}_{k}$ can then be obtained by interpolating between the fixed observer gains $\boldsymbol{L}_{\mathrm{v}, j}$ through:

$$
\boldsymbol{L}_{k}=\sum_{j=1}^{M} \lambda_{j, k} \boldsymbol{L}_{\mathrm{v}, j}
$$

\subsection{Calculation of observer vertex gains}

In this section, sufficient conditions for the observer gains of the vertex systems are stated that guarantee asymptotic stability of the observer and a certain performance level. Here, the $\mathrm{H}_{2}$-norm of the transfer path from a noise input to the observer error is chosen as performance measure.

It is assumed that white noise of unit variance, given by the signals $\boldsymbol{w}_{1}$ and $\boldsymbol{w}_{2}$ and weighted by matrices $\boldsymbol{Q}^{1 / 2}$ and $\boldsymbol{R}^{1 / 2}$ respectively, affects the states and the outputs of the vertex systems:

$$
S_{\mathrm{v}, j}=\left[\begin{array}{c|c}
\boldsymbol{A}_{\mathrm{v}, j} & \boldsymbol{B} \\
\hline \boldsymbol{C} & \mathbf{0}
\end{array}\right], j=1, \ldots, M .
$$

This yields:

$$
\begin{aligned}
& \boldsymbol{x}_{k+1}=\boldsymbol{A}_{\mathrm{v}, j} \boldsymbol{x}_{k}+\boldsymbol{B} u_{k}+\boldsymbol{Q}^{1 / 2} \boldsymbol{w}_{1, k}, \\
& y_{k}=\boldsymbol{C} \boldsymbol{x}_{k}+\boldsymbol{R}^{1 / 2} \boldsymbol{w}_{2, k}
\end{aligned}
$$

for $j=1, \ldots, M$. An identity observer with observer gain $\boldsymbol{L}_{\mathrm{v}, j}$ is given by:

$$
\hat{\boldsymbol{x}}_{k+1}=\left(\boldsymbol{A}_{\mathrm{v}, j}-\boldsymbol{L}_{\mathrm{v}, j} \boldsymbol{C}\right) \hat{\boldsymbol{x}}_{k}+\boldsymbol{B} u_{k}+\boldsymbol{L}_{\mathrm{v}, j} y_{k} .
$$

With (25) and (26), the dynamics of the observer error are:

$$
\tilde{\boldsymbol{x}}_{k+1}=\left(\boldsymbol{A}_{\mathrm{v}, k}-\boldsymbol{L}_{\mathrm{v}, j} \boldsymbol{C}\right) \tilde{\boldsymbol{x}}_{k}+\left[\begin{array}{ll}
\boldsymbol{Q}^{1 / 2} & -\boldsymbol{L}_{\mathrm{v}, j} \boldsymbol{R}^{1 / 2}
\end{array}\right] \boldsymbol{w}_{k}
$$

where $\boldsymbol{w}_{k}=\left[\begin{array}{ll}\boldsymbol{w}_{1, k}^{\mathrm{T}} & \boldsymbol{w}_{2, k}^{\mathrm{T}}\end{array}\right]^{\mathrm{T}}$.

Constraints for quadratic stability of the observer and an upper bound on the $\mathrm{H}_{2}$ norm of the transfer path from the noise input $\boldsymbol{w}$ to the observer error $\tilde{\boldsymbol{x}}$ can be expressed as LMIs, which are briefly reviewed here. The $\mathrm{H}_{2}$ norm of a stable discrete-time LTI system

$$
G=\left[\begin{array}{l|l}
\boldsymbol{A} & \boldsymbol{B} \\
\hline \boldsymbol{C} & \mathbf{0}
\end{array}\right]
$$

is given by:

$$
\|G(z)\|_{2}^{2}=\operatorname{trace}\left(\boldsymbol{B}^{\mathrm{T}} \boldsymbol{W}_{\mathrm{o}} \boldsymbol{B}\right),
$$

with observability gramian $\boldsymbol{W}_{\mathrm{o}}$, which is the solution of:

$$
\boldsymbol{A}^{\mathrm{T}} \boldsymbol{W}_{\mathrm{o}} \boldsymbol{A}-\boldsymbol{W}_{\mathrm{o}}+\boldsymbol{C}^{\mathrm{T}} \boldsymbol{C}=0 .
$$

Therefore, if matrices $\boldsymbol{P}=\boldsymbol{P}^{\mathrm{T}}>0$ and $\boldsymbol{W}=\boldsymbol{W}^{\mathrm{T}}>0$ exist, such that:

$$
\begin{aligned}
& \boldsymbol{A}^{\mathrm{T}} \boldsymbol{P} \boldsymbol{A}-\boldsymbol{P}+\boldsymbol{C}^{\mathrm{T}} \boldsymbol{C}<0, \\
& \boldsymbol{W}-\boldsymbol{B}^{\mathrm{T}} \boldsymbol{P} \boldsymbol{B}>0, \\
& \operatorname{trace}(\boldsymbol{W})<\gamma^{2},
\end{aligned}
$$

it follows that $\|G(z)\|_{2}<\gamma$ for $\gamma>0$. Through the Schur complement, (32) and (33) can be transformed to: 


$$
\begin{aligned}
& {\left[\begin{array}{cc}
\boldsymbol{P} & \boldsymbol{P} \boldsymbol{A} \\
\boldsymbol{A}^{\mathrm{T}} \boldsymbol{P} & \boldsymbol{P}-\boldsymbol{C}^{\mathrm{T}} \boldsymbol{C}
\end{array}\right]>0,} \\
& {\left[\begin{array}{cc}
\boldsymbol{W} & \boldsymbol{B}^{\mathrm{T}} \boldsymbol{P} \\
\boldsymbol{P} \boldsymbol{B} & \boldsymbol{P}
\end{array}\right]>0}
\end{aligned}
$$

Applying this to the observer approach from Sec. 3.1 and introducing:

$$
\boldsymbol{Q}_{\mathrm{t}}=\left[\begin{array}{c}
\boldsymbol{Q}^{\mathrm{T} / 2} \\
\mathbf{0}
\end{array}\right], \boldsymbol{R}_{\mathrm{t}}=\left[\begin{array}{c}
\mathbf{0} \\
\boldsymbol{R}^{\mathrm{T} / 2}
\end{array}\right] \text { and } \boldsymbol{Y}_{\mathrm{v}, j}=\boldsymbol{L}_{\mathrm{v}, j}^{\mathrm{T}} \boldsymbol{P},
$$

it follows that if:

$$
\begin{aligned}
& {\left[\begin{array}{cc}
\boldsymbol{P} & \boldsymbol{P} \boldsymbol{A}_{\mathrm{v}, j}-\boldsymbol{Y}_{\mathrm{v}, j}^{\mathrm{T}} \boldsymbol{C} \\
\left(\boldsymbol{P} \boldsymbol{A}_{\mathrm{v}, j}-\boldsymbol{Y}_{\mathrm{v}, j}^{\mathrm{T}} \boldsymbol{C}\right)^{\mathrm{T}} & \boldsymbol{P}-\mathbf{I}
\end{array}\right]>0,} \\
& {\left[\begin{array}{cc}
\boldsymbol{W} & \boldsymbol{Q}_{\mathrm{t}} \boldsymbol{P}-\boldsymbol{R}_{\mathrm{t}} \boldsymbol{Y}_{\mathrm{v}, j} \\
\left(\boldsymbol{Q}_{\mathrm{t}} \boldsymbol{P}-\boldsymbol{R}_{\mathrm{t}} \boldsymbol{Y}_{\mathrm{v}, j}\right)^{\mathrm{T}} & \boldsymbol{P}
\end{array}\right]>0}
\end{aligned}
$$

hold for all $j=1, \ldots, M$ and also (34) is fulfilled, then the transfer function from the noise input $\boldsymbol{w}$ to the observation error $\tilde{\boldsymbol{x}}$ given by (28) has a $H_{2}$ norm bounded by $\gamma$. The observer gain for each vertex system $S_{v, j}$ for $j=1, \ldots, M$ is then given by:

$$
\boldsymbol{L}_{\mathrm{v}, j}=\boldsymbol{P}^{-1} \boldsymbol{Y}_{\mathrm{v}, j}^{\mathrm{T}}
$$

Because of (32), quadratic and therefore asymptotic stability of the observers is implied. Solutions for the matrix variables $\boldsymbol{P}$ and $\boldsymbol{W}$ in (34), (38) and (39) have to be the same for all vertex systems in order to guarantee quadratic stability for the whole parameter space, as presented in Sec. 3.2. Therefore, if solutions are found, also the performance bound $\gamma$ is guaranteed for all systems:

$$
\hat{\boldsymbol{x}}_{k+1}=(\boldsymbol{A}(\boldsymbol{\theta})-\boldsymbol{L}(\boldsymbol{\theta}) \boldsymbol{C}) \hat{x}_{k}+\boldsymbol{B} \boldsymbol{u}_{k}+\boldsymbol{L}(\boldsymbol{\theta}) y_{k}
$$

with $\theta \in \Theta$, since the upper bound on the performance depends only on $\boldsymbol{P}$ and $\boldsymbol{W}$. It is, however, not straightforward to interpret an $\mathrm{H}_{2}$ performance bound in the time-varying case.

\subsection{Disturbance model}

The disturbance is assumed to be a multisine with $N$ components of the disturbance and $f_{i, k}$ to be the frequency of the $i$-th component at sampling instant $k$. The frequencies are assumed to vary in intervals $\left[f_{i, \text { min }}, f_{i, \text { max }}\right] \subseteq\left[0,0.5 f_{s}\right]$, where $f_{s}$ denotes the sampling frequency. Such disturbance can be modelled similar to (2) by choosing:

$$
\begin{aligned}
\boldsymbol{A}_{\mathrm{d}, k} & =\left[\begin{array}{ccc}
\boldsymbol{A}_{\mathrm{d}_{1}, k} & \cdots & \mathbf{0} \\
\vdots & \ddots & \vdots \\
\mathbf{0} & \cdots & A_{\mathrm{d}_{N}, k}
\end{array}\right], \\
\boldsymbol{A}_{\mathrm{d}_{i}, k} & =\left[\begin{array}{cc}
\cos \left(2 \pi f_{i, k} T\right) & \sin \left(2 \pi f_{i, k} T\right) \\
-\sin \left(2 \pi f_{i, k} T\right) & \cos \left(2 \pi f_{i, k} T\right)
\end{array}\right],
\end{aligned}
$$

where $T=1 / f_{s}$ is the sampling time, and:

$$
\boldsymbol{C}_{\mathrm{d}}=\left[\begin{array}{lll}
\boldsymbol{C}_{\mathrm{d}_{1}} & \cdots & \boldsymbol{C}_{\mathrm{d}_{N}}
\end{array}\right], \boldsymbol{C}_{\mathrm{d}_{i}}=\left[\begin{array}{ll}
1 & 0
\end{array}\right], i=1, \ldots, N .
$$

The dynamics of the disturbance for time-varying frequencies can be given by (42) and (43), it takes into account the rate of change of the frequency. Nevertheless, for the sake of reduction in the number of parameters, therefore a reduction in the number of calculations, an 'incorrect' model is used here since it is slightly simpler. It is based on the disturbance model for constant frequencies:

$$
\begin{aligned}
\boldsymbol{A}_{\mathrm{d}_{i}, k} & =\left[\begin{array}{cc}
0 & 1 \\
-1 & 2 \theta_{i, k}
\end{array}\right], \\
\theta_{i, k} & =\cos \left(2 \pi f_{i, k} T\right) .
\end{aligned}
$$

This change does not affect the performance of the system for constant disturbance frequencies or the closed-loop stability. It might affect the disturbance attenuation for fast changes in the disturbance frequency, although this simplified model has been used for the rejection of time-varying frequencies (Shu et al. 2011, Ballesteros and Bohn 2011a, 2011b, Heins et al. 2011, 2012a, 2012b, Ballesteros et al. 2012, Duarte et al. 2013). In most practical applications with time-varying frequencies, however, the measured frequency will not correspond exactly to the instantaneous frequency due to measurement delays and the transmission of the disturbance to the plant. It is then unclear whether using the correct model would result in better performance.

Using the simplified disturbance model (45) allows a direct formulation of $\boldsymbol{A}_{\mathrm{d}, k}$ in $\mathrm{pLPV}$ form with one parameter per frequency. With $\boldsymbol{\theta}$ given by (46), then:

$$
\mathcal{A}_{\mathrm{d}_{0}}=\left[\begin{array}{ccc}
\mathcal{A}_{\mathrm{d}_{0}, 1} & \cdots & \mathbf{0} \\
\vdots & \ddots & \vdots \\
\mathbf{0} & \cdots & \mathcal{A}_{\mathrm{d}_{0}, N}
\end{array}\right], \mathcal{A}_{\mathrm{d}_{0}, i}=\left[\begin{array}{cc}
0 & 1 \\
-1 & 0
\end{array}\right]
$$

and $\mathcal{A}_{\mathrm{d}_{i}}$ matrices with zero entries only except for:

$$
\mathcal{A}_{\mathrm{d}_{i}}(2 i, 2 i)=2, i=1, \ldots, N \text {. }
$$

The matrix $\boldsymbol{A}_{\mathrm{d}, k}$ can be written as an affine function of $\boldsymbol{\theta}$ according to:

$$
\boldsymbol{A}_{\mathrm{d}, k}=\boldsymbol{A}_{\mathrm{d}}\left(\boldsymbol{\theta}_{k}\right)=\mathcal{A}_{\mathrm{d}_{0}}+\theta_{1, k} \mathcal{A}_{\mathrm{d}_{1}}+\ldots+\theta_{N, k} \mathcal{A}_{\mathrm{d}_{N}} .
$$

Due to the sampling theorem, it holds that $0 \leq 2 \pi f_{i, k} T \leq \pi$ for all $i=1, \ldots, N$ and therefore the parameters $\theta_{i, k}$ vary in a range of $\left[\theta_{i, \min }, \theta_{i, \max }\right]$ with:

$$
\theta_{i, \text { min }}=\cos \left(2 \pi f_{i, \text { max }} T\right), \theta_{i, \text { max }}=\cos \left(2 \pi f_{i, \text { min }} T\right),
$$

since the cosine is a monotonically decreasing function on $[0, \pi]$. Therefore, the parameter vector $\boldsymbol{\theta}_{k}$ varies in an $N$-dimensional hyperbox:

$$
\Theta=\left[\theta_{1, \text { min }}, \theta_{1, \text { max }}\right] \times\left[\theta_{2, \text { min }}, \theta_{2, \text { max }}\right] \times \ldots \times\left[\theta_{N, \text { min }}, \theta_{N, \text { max }}\right]
$$

with $M=2^{N}$ vertices. 


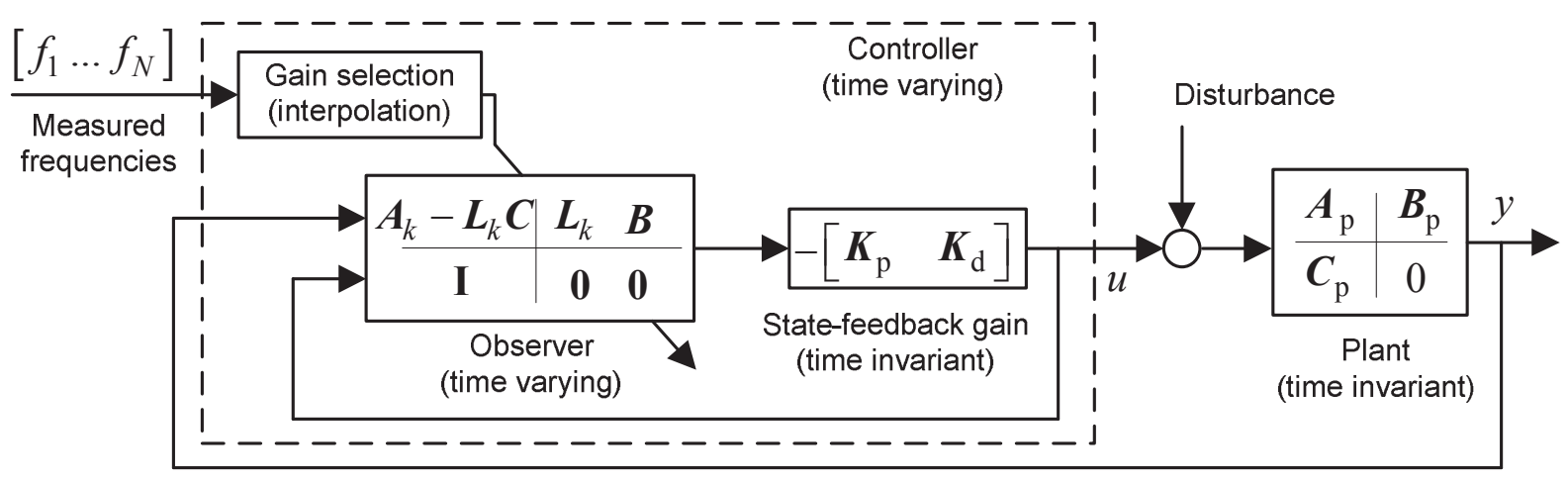

Fig. 2. Control system structure

\section{CONTROLLER IMPLEMENTATION}

Once the pLPV representation of the considered system is found, observer gains $\boldsymbol{L}_{\mathrm{v}, j}$ for vertex systems can be computed off-line. Since the plant is LTI, the state-feedback gain for the plant states can also be designed off-line with a standard method (e.g. LQR or pole placement). The observer gain $\boldsymbol{L}_{k}$ is obtained by interpolation from the time-varing vector $\lambda_{k}$. A scheme of the observer-based gain-scheduling controller is shown in figure 2. The gain-scheduling state-space representation of the implemented controller is given by:

$$
\left[\begin{array}{c}
\boldsymbol{x}_{\mathrm{c}, k+1} \\
\hline u_{k}
\end{array}\right]=\left[\begin{array}{c|c}
\boldsymbol{A}_{\mathrm{c}}\left(\boldsymbol{\lambda}_{k}\right) & \boldsymbol{B}_{\mathrm{c}}\left(\boldsymbol{\lambda}_{k}\right) \\
\hline \boldsymbol{C}_{\mathrm{c}} & 0
\end{array}\right]\left[\begin{array}{c}
\boldsymbol{x}_{\mathrm{c}, k} \\
\hline y_{k}
\end{array}\right]
$$

with system matrices:

$$
\begin{aligned}
& \boldsymbol{A}_{\mathrm{c}}\left(\boldsymbol{\lambda}_{k}\right)=\sum_{j=1}^{M} \lambda_{j, k}\left(\boldsymbol{A}_{\mathrm{v}, j}-\boldsymbol{L}_{\mathrm{v}, j} \boldsymbol{C}\right)-\boldsymbol{B} \boldsymbol{K}, \\
& \boldsymbol{B}_{\mathrm{c}}\left(\boldsymbol{\lambda}_{k}\right)=\sum_{j=1}^{M} \lambda_{j, k} \boldsymbol{L}_{\mathrm{v}, j}
\end{aligned}
$$

and

$$
\boldsymbol{C}_{\mathrm{c}}=-\boldsymbol{K} \text {. }
$$

The coordinates $\lambda_{k}$ required for interpolation can be computed following the scheme that is introduced by Apkarian et al. (2006), generalized and implemented for an arbitrary number of vertices in the LMI Control Toolbox for Matlab (Apkarian et al. 1995). Another way of implementation is proposed here that is suitable for real-time implementation purposes where variables have to be pre-initialized with fixed dimensions. In Daafouz et al. (2000), a compact way of writing the calculation scheme is presented, on which the scheme proposed here is based. If the order of vertices is not changed, each approach leads to the same coordinates.

The $i$-th entry $v_{j, i}$ of a vertex $\boldsymbol{v}_{j}=\left[\begin{array}{lll}v_{j, 1} & \cdots & v_{j, N}\end{array}\right]^{\mathrm{T}}$ of the parameter box $\Theta$ is either the lower bound $\theta_{i, \min }$ or the upper bound $\theta_{i, \max }$ of $\theta_{i, k}$. Now, $2 N$ vectors:

$$
\begin{aligned}
& \boldsymbol{b}_{i_{\max }}=\left[\begin{array}{lll}
b_{i_{\max }, 1} & \cdots & b_{i_{\max }, M}
\end{array}\right]^{\mathrm{T}}, \\
& \boldsymbol{b}_{i_{\min }}=\left[\begin{array}{llll}
b_{i_{\min }, 1} & \cdots & b_{i_{\min }, M}
\end{array}\right]^{\mathrm{T}},
\end{aligned}
$$

are pre-computed such that:

$$
\begin{aligned}
& b_{i_{\max }, j}=\left\{\begin{array}{cl}
1 /\left(\theta_{i, \max }-\theta_{i, \min }\right), & \text { if } v_{j, i}=\theta_{i, \max }, \\
0, & \text { if } v_{j, i}=\theta_{i, \min },
\end{array}\right. \\
& b_{i_{\min }, j}=\left\{\begin{array}{cl}
1 /\left(\theta_{i, \max }-\theta_{i, \min }\right), & \text { if } v_{j, i}=\theta_{i, \min }, \\
0, & \text { if } v_{j, i}=\theta_{i, \max }
\end{array}\right.
\end{aligned}
$$

The following steps are then carried out on-line in every sampling instant:

1. $\theta_{i, k}=\cos \left(2 \pi f_{i, k} T\right), i=1, \ldots, N$,

2. $c_{i_{\max }, k}=\theta_{i, k}-\theta_{i, \min }, c_{i_{\min }, k}=\theta_{i, \max }-\theta_{i, k}, i=1, \ldots, N$,

3. $\lambda_{j, k}=\prod_{i=1}^{N}\left(b_{i_{\max }, j} c_{i_{\max }, k}+b_{i_{\min }, j} c_{i_{\min }, k}\right), j=1, \ldots, M$.

The choice of the coordinates ${ }_{k}$ is not unique for a polytope with more than three vertices. Another interpolation scheme might lead to different properties of the resulting controller.

\section{EXPERIMENTAL SETUP}

To study the suitability of this design approach for AVC of flexible structures, a test bed was designed. The scheme of this experimental setup is shown in figures 3 and 4 , and a photograph of the system in figure 5. It consists of a clamped aluminium beam of dimensions $400 \times 35 \times 2 \mathrm{~mm}$, two piezoelectric actuators (P 876.A12 DuraAct), two piezo amplifiers (PI E413.D2), a rapid control prototyping hardware (dSPACE 1104) and an accelerometer (ASC 4411LN). An anti-aliasing filter is used for the signal of the accelerometer and two reconstruction filters for the output signal of the controller. A speed laser vibrometer (PDV-100) was also used as a parallel measurement to verify the effectiveness of the control algorithm. The harmonic disturbance is generated using two DC motor-encoder combinations (Maxon Motors) and two four quadrant P+I speed velocity controllers (ESCON 36/2 DC). These motors are provided with unbalanced pulleys. The amplitude of the disturbances can be calculated according to:

$$
F_{d}=m_{p} r_{G}\left(2 \pi f_{i}\right)^{2} \cos \left(2 \pi f_{i} t\right) .
$$




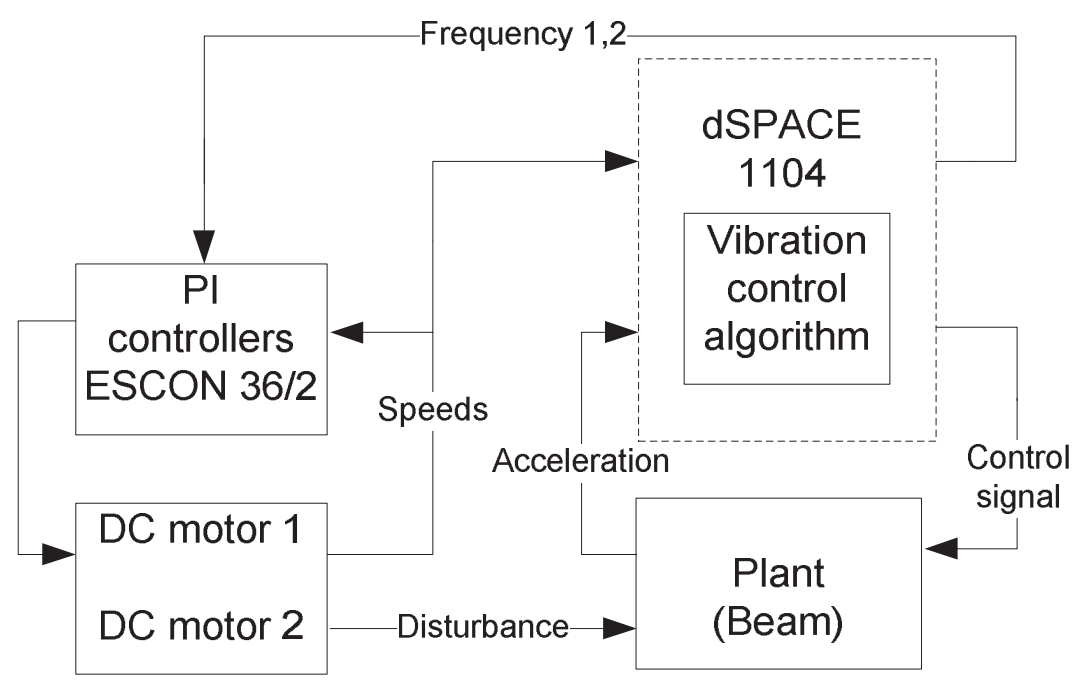

Fig. 3. Schematic control architecture of the experimental setup

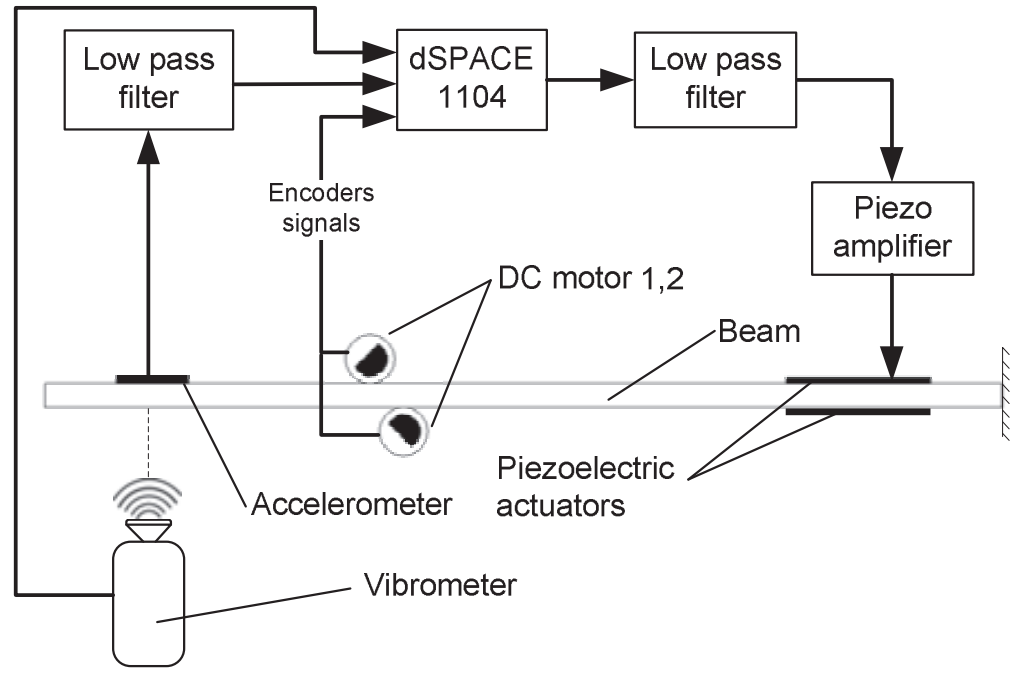

Fig. 4. Schematic diagram of the experimental setup

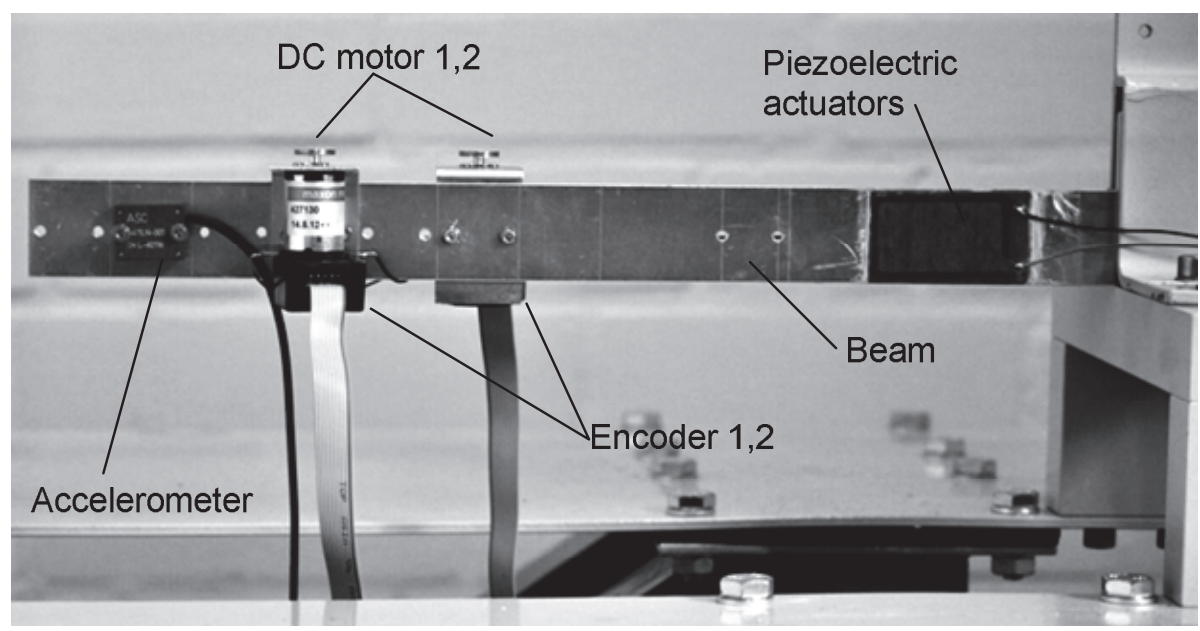

Fig. 5. Experimental test bed 
There are two different configurations under consideration in the test bench: a system with one DC motor (system 1) and the other system with two DC motors (system 2). The disturbance amplitudes for a range of frequency variation for the different system configurations are presented in table 1 .

Table 1

Parameters of the experiments

\begin{tabular}{|c|c|l|l|}
\hline Syst. & Dist. & Min. amplitude & Max. amplitude \\
\hline 1 & 1 & $0.168 \mathrm{~N} @ 25 \mathrm{~Hz}$ & $0.328 \mathrm{~N} @ 35 \mathrm{~Hz}$ \\
\hline \multirow{2}{*}{2} & 1 & $0.040 \mathrm{~N} @ 21 \mathrm{~Hz}$ & $0.024 \mathrm{~N} @ 27 \mathrm{~Hz}$ \\
\cline { 2 - 4 } & 2 & $0.184 \mathrm{~N} @ 31 \mathrm{~Hz}$ & $0.130 \mathrm{~N} @ 37 \mathrm{~Hz}$ \\
\hline
\end{tabular}

The controller calculated in Section 3 uses the measured frequencies from the encoders and the signal from the accelerometer to generate the control signal. The patch piezoelectric actuators are symmetrically placed to the flexural neutral axis of the beam in order to obtain a maximal applied bending moment, where the control signal to each patch is inverted with respect to the other. The longitudinal location of the actuators was defined according to the principle of maximal modal deformation (Gupta et al. 2010).

\section{EXPERIMENTAL RESULTS}

The controllers obtained from the design procedure of Section 3 with the polytopic disturbance model are validated experimentally on a test bed described in Section 5. A sampling frequency of $1 \mathrm{kHz}$ was chosen such that the Nyquist frequency of $500 \mathrm{~Hz}$ is well above the highest disturbance frequency. The discrete-time transfer functions between the output and the input of the control unit are obtained using standard black-box techniques for system identification. AVC systems including piezoelectric actuators usually exhibit nonlinear behaviour (actuator saturation, hysteresis (Tilba and Var- nier 2010)); however, for the application considered here, a linear model was suitable, partially due to the fact that the disturbance amplitudes were sufficiently small.

Two sets of experiments were performed to verify the effectiveness of the proposed controllers. The first set consists of two experiments to prove the capability of rejection of time-varying harmonic disturbances. The second set consists also of two experiments to prove the capability of rejection of transient disturbances.

\subsection{Rejection of time-varying harmonic disturbances}

For the first experiment, the identified model is of $13^{\text {th }}$ order. It is disturbed just with one harmonic signal (one DC motor installed). This gives a $2^{\text {nd }}$ order disturbance model and a parameter variation in $\mathbf{R}$ with two vertices. The resulting controller is of $15^{\text {th }}$ order. For the second experiment the identified model is of $15^{\text {th }}$ order, it is disturbed with two independent harmonic signals (two DC motors installed). This gives a $4^{\text {th }}$ order disturbance model and a parameter variation in $\mathbf{R}^{2}$ with four vertices. The resulting controller is of $19^{\text {th }}$ order.

The open-loop and closed-loop amplitude frequency response for a disturbance with one fixed frequency $(28 \mathrm{~Hz})$ and for two fixed frequencies $(21 \mathrm{~Hz}$ and $31 \mathrm{~Hz})$ are shown in figure 6 . The amplitude - frequency responses are scaled to acceleration over voltage, since the voltage is approximately proportional to the actuator's bending moment. The amplitude response plots show that amplification takes place in frequency ranges near the rejected frequencies. This is due to Bode's sensitivity integral ('waterbed' effect) e.g. disturbance rejection in one frequency region usually results in disturbance amplification in other frequency regions. Thus, if disturbances are present with significant spectral contributions outside the frequency region specified in the disturbance model (such as broadband stochastic noise). The additional objective that the disturbance amplification must not be too severe might have to be included. This would lead to a multiobjective design. It can also be expected that such a design includes the synthesis of the state-feedback gain.
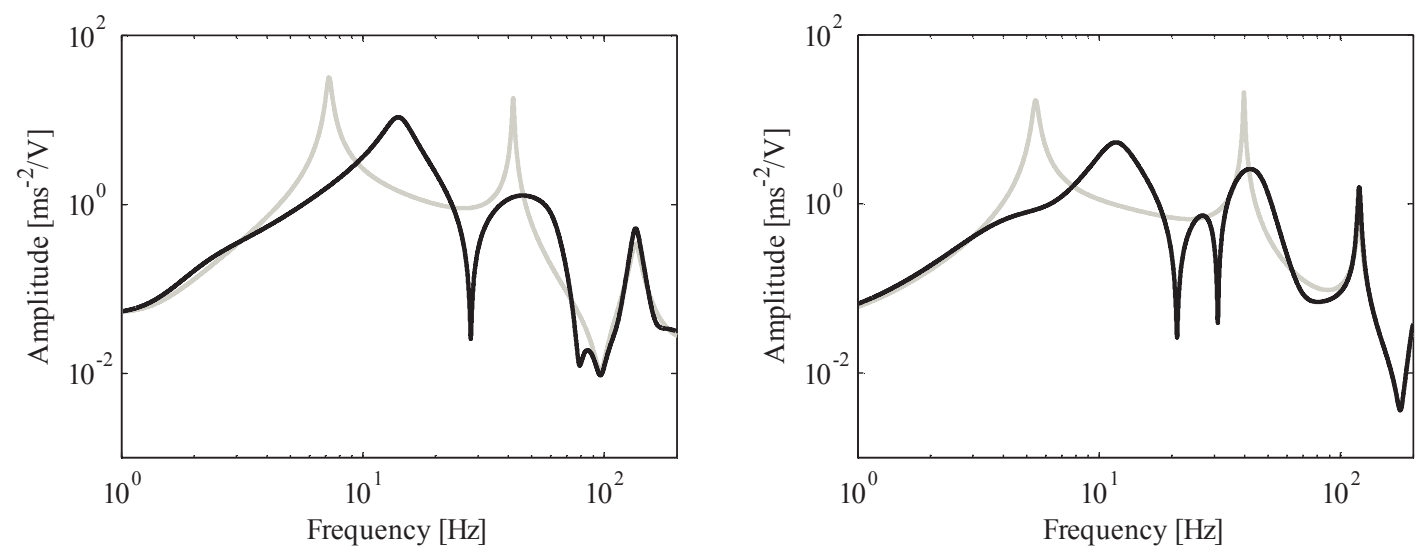

Fig. 6. Left: Amplitude frequency response in open loop (gray) and closed loop (black) for one harmonic disturbance with fixed frequency. Right: Frequency response in open loop (gray) and closed loop (black) for two harmonic disturbances with fixed frequencies 
The focus of this paper however lies on the rejection of sinusoidal disturbances only and therefore, these issues are outside the scope of this work.

In figure 7, the variations of the frequencies over time for the first set of experiments are shown. In figures 8 and 9, excellent rejection of the disturbances is shown for different rates of change in the frequency of the disturbances. For the case of two frequencies the performance of the rejection is not as good as for the case of single frequency; it is because the disturbances are independent from each other. In these figures it can be also seen that the rate of variation has an influence on the rejection of the disturbances. For this test bed
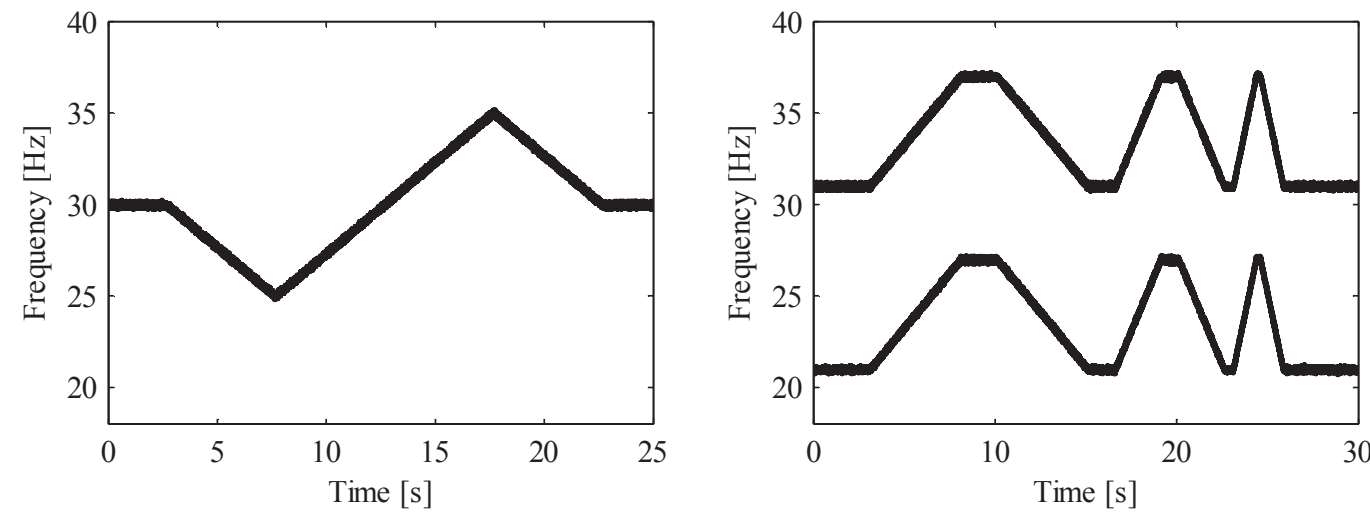

Fig. 7. Linear frequency variation of harmonic disturbance. Left: One disturbance. Right: Two disturbances
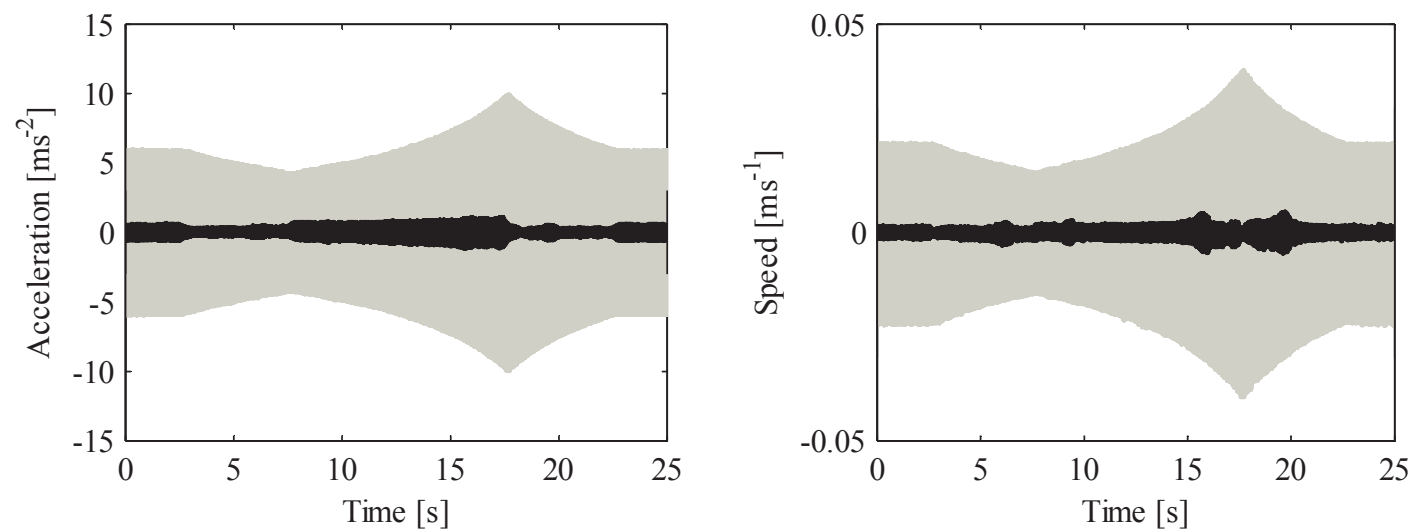

Fig. 8. Response measured at the tip of the beam in open loop (gray) and closed loop (black) for a disturbance with linear frequency variation. Left: From accelerometer. Right: From laser vibrometer
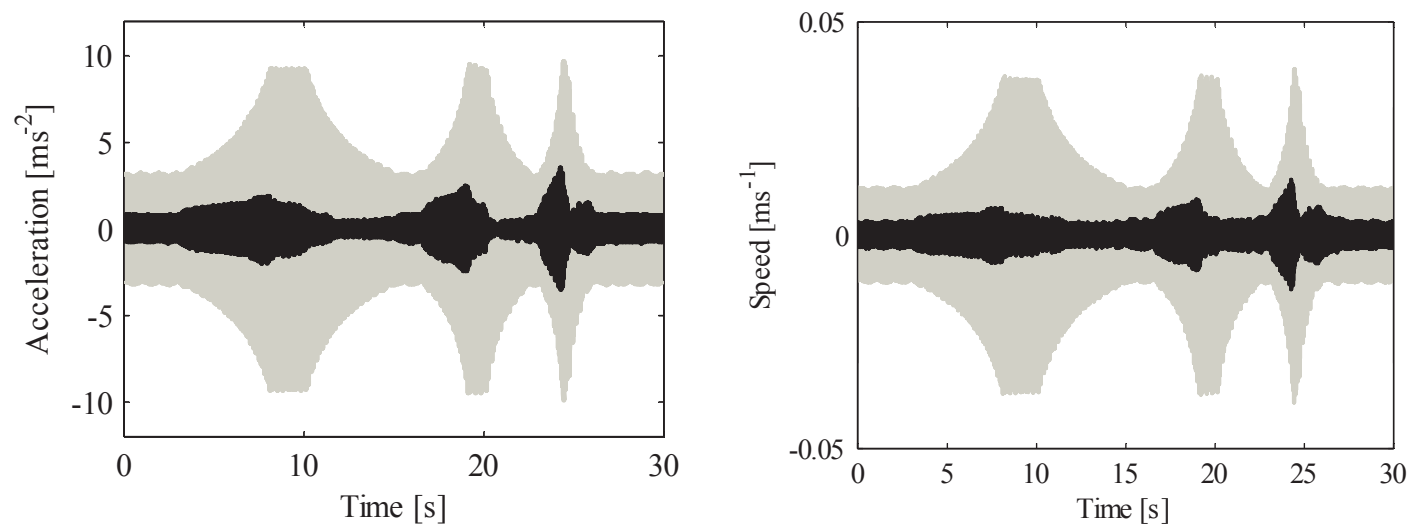

Fig. 9. Response measured at the tip of the beam in open loop (gray) and closed loop (black) for two disturbances with linear frequency variations. Left: From accelerometer. Right: From laser vibrometer 

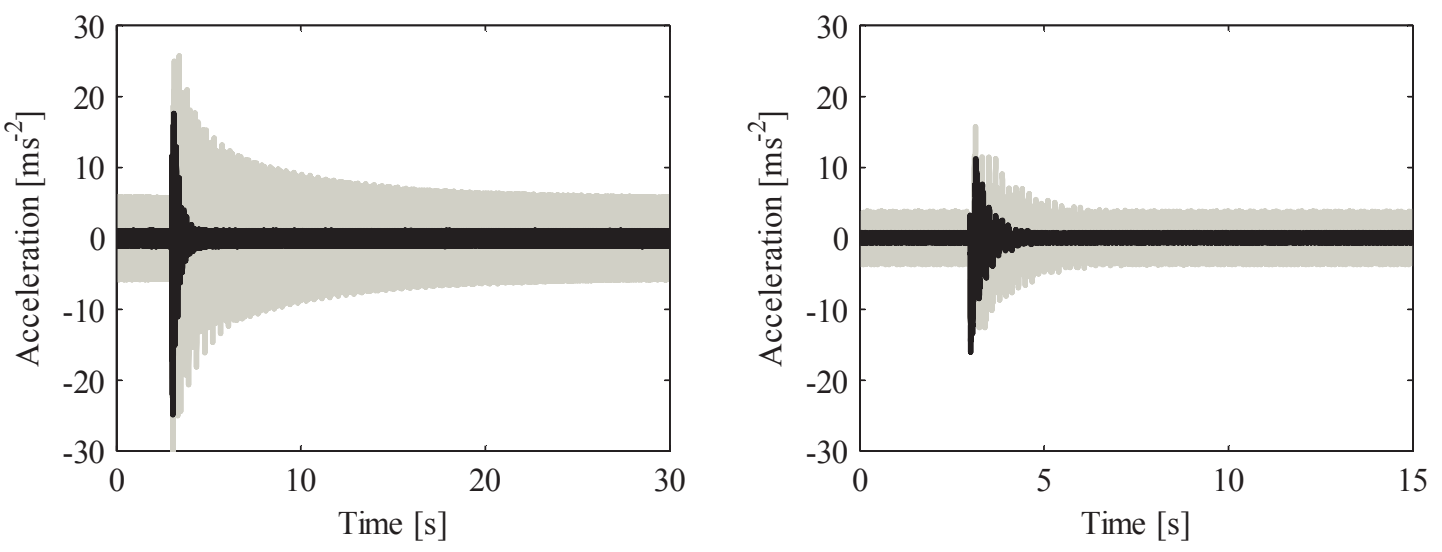

Fig. 10. Acceleration measured at the tip of the beam in open loop (gray) and closed loop (black) for a transient disturbance. Left: A harmonic disturbance $(30 \mathrm{~Hz})$. Right: Two harmonic disturbances $(23$ and $33 \mathrm{~Hz}$ )

it could be due to the time constant of the DC motor, the motors are not capable to react to fast changes in its speed, therefore, there could be a delay between the measured frequency and the real frequency. Nevertheless, the system remains stable for fast changes in the frequencies of the disturbances.

\subsection{Rejection of transient disturbances}

In this set of experiments a transient disturbance is added to the system in the form of an impact at the tip of the beam. This impact excites the beam, where the first mode of vibration has a predominant effect. The inclusion of a time-invariant feedback for the plant states in the controller damps the first two modes of vibration of the beam. The controller is turned on for the rejection of constant harmonic disturbances, after a few seconds a transient disturbance is applied. In figures 10 the results for both systems are shown.

The transient disturbance applied to each system has the same linear momentum. The second system has more moment of inertia (on which two DC motors are installed), that's why the effect of the disturbance is smaller. Good transient disturbance rejection is achieved as it was expected from the frequency responses.

\section{CONCLUSIONS}

Two discrete-time pLPV observer-based state-feedback controllers for the rejection of harmonic disturbances with time-varying frequencies in a smart structure are presented. The control design methods are based on quadratic stability theory for pLPV systems. The controller is found by solving a set of LMIs. Stability of the closed-loop system is ensured even for arbitrarily fast changes of parameters.

The experimental results show that excellent disturbance rejection is achieved for constant frequencies, for time-varying frequencies and the transient performance is improved at the same time.

\section{References}

Amato F. 2006, Robust control of linear systems subject to uncertain time-varying parameters, Springer, Berlin.

Apkarian P., Gahinet P., Becker G. 1995, Self-scheduled $H_{\alpha}$ control of linear parameter-varying systems: A design example, Automatica, vol. 31, no. 9, pp. 1251-1261.

Ballesteros P., Bohn C. 2011a, A frequency-tunable LPV controller for carrowband active noise and vibration control. Proc. of the Am. Control Conf., San Francisco, USA, Jun. 2011, pp. 1340-1345.

Ballesteros P., Bohn C. 2011b, Disturbance rejection through LPV gain-scheduling control with application to active noise cancellation. Proc. of the IFAC World Congr., Milan, Italy, Aug. 2011, pp. 7897-7902.

Ballesteros P., Heins W., Shu X., Bohn C. 2012, LPV Gain-scheduling output feedback for active control of harmonic disturbances with time-varying frequencies. [in:] Zapateiro M., Pozo F. (eds.), Advances on Analysis and Control of Vibrations - Theory and Applications, InTech, Rijeka, Croatia, pp. 65-86. Available: http://dx.doi.org/10.5772/ 50294

Ballesteros P., Shu X., Heins W., Bohn C. 2013, Reduced-order two-parameter pLPV controller for the rejection of nonstationary harmonically related multisine disturbances. Proc. of the Eur. Control Conf., Zurich, Switzerland, July 2013, pp. 1835-1842.

Bohn C., Cortabarria A., Härtel V., Kowalczyk K. 2003, Disturbance-observer-based active control of engine-induced vibrations in automotive vehicles. Proc. of the SPIE's 10th Annu. Int. Symp. on Smart Struct. and Mater., San Diego, USA, Mar. 2003, pp. 5049-5068.

Bohn C., Cortabarria A., Härtel V., Kowalczyk K. 2004, Active control of engine-induced vibrations in automotive vehicles using disturbance observer gain scheduling. Control Eng. Pract., vol. 12, no. 8, pp. 1029 1039.

Daafouz J., Bara G., Kratz F., Ragot J. 2000, State observers for discrete-time LPV systems: an interpolation based approach. Proc. of the 39th IEEE Conf. on Decis. and Control, Sydney, Australia, Dec. 2000, vol. 5, pp. 4571-4572.

Dettori M., Scherer C. 2001, LPV design for a CD player: an experimental evaluation of performance. Proc. of the 40th IEEE Conf. on Decis. and Control, Orlando, USA, Dec. 2001, pp. 4711-4716.

Du H., Zhang L., Shi X. 2003, LPV technique for the rejection of sinusoidal disturbance with time-varying frequency. IEE Proc.-Control Theory and Appl., vol. 150, no 2, pp. 132-138.

Duarte F., Ballesteros P., Shu X., Bohn C. 2012, Active control of the harmonic and transient response of vibrating flexible structures with piezoelectric actuators. Proc. of the Int. Conf. and Exhib. of New Actuators and Drive Syst. ACTUATOR 12, Bremen, Germany, June 2012, pp. $447-450$.

Duarte F., Ballesteros P., Shu X., Bohn C. 2013, An LPV discrete-time controller for the rejection of harmonic time-varying disturbances in a lightweight flexible structure. Proc. of the Am. Control Conf., Washington, USA, June 2013, pp. 4092-4097. 
Francis B., Wonham W. 1976, The internal model principle of control theory. Automatica, vol. 12 , no. 5, pp. 457-465.

Gahinet P., Nemirovskii A., Laub A., Chilali M. 1995, LMI control toolbox. The Mathworks Inc.

Gupta V., Sharma M., Thakur N., 2010, Optimization criteria for optimal placement of piezoelectric sensors and actuators on a smart structure: a technical review. J. Intell. Mater. Syst. and Struct., vol. 21, no. 12, pp. 1227-1243.

Heins W., Ballesteros P., Bohn C. 2011, Gain-scheduled state-feedback control for active cancellation of multisine disturbances with time-varying frequencies. Proc. of the 10th MARDiH Conf. on Active Noise and Vib. Control Methods, Wojanow, Poland, June 2011, pp. 45-62. Available: http://www.vibrationcontrol.pl/ file/pdfs/p45. pdf

Heins W., Ballesteros P., Bohn C. 2012a, Experimental evaluation of an $L P V$-gain-scheduled observer for rejecting multisine disturbances with time-varying frequencies. Proc. of the Am. Control Conf., Montreal, Canada, June 2012, pp. 768-774

Heins W., Ballesteros P., Shu X., Bohn C. 2012b, LPV Gain-scheduled Observer-based State Feedback for Active Control of Harmonic Disturbances with Time-varying Frequencies. [in:] Zapateiro M., Pozo F. (eds.), Advances on Analysis and Control of Vibrations - Theory and Applications, InTech, Rijeka, Croatia, pp. 35-64. Available: http://dx.doi.org/10.5772/50293

Kermani M., Moallem M. Patel R. 2008, Applied vibration suppression using piezoelectric materials. Nova, New York.

Kinney C., Callafon R. 2006, An adaptive internal model-based controller for periodic disturbance rejection. Proc. of the 14th IFAC Symp. on Syst. Identif., Newcastle, Australia, Mar. 2006, pp. 273-278.

Kuo S., Morgan D. 1996, Active noise control systems: algorithms and DSP implementations. Wiley, New York.
Oh J., Park S., Hong J., Shin J. 1998, Active vibration control of flexible cantilever beam using piezo actuator and filtered-X LMS algorithm. KSME Int. J., vol. 12, no. 6, pp. 665-671.

Onat C., Sahin M., Yaman Y., Prasad S., Nemana S. 2011, Design of an LPV based fractional controller for the vibration suppression of a smart beam. Int. Workshop Smart Mater., Struct. \& NDT in Aerosp., Montreal, Canada, Nov. 2011.

Shouwe G., Zhiyuan G., Yong S., Jincong Y., Xiaojin Z. 2010, Performance analysis and comparison of FXLMS and FULMS algorithm for active structure vibration control. Proc. of the 2nd Int. Conf. on Adv. Comput. Control, Shenyang, China, Mar. 2010, pp. 197-201.

Shu X., Ballesteros P., Bohn C. 2011, Active vibration control for harmonic disturbances with time-varying frequencies through LPV gain scheduling. Proc. of the 23rd Chin. Control and Decis. Conf., Mianyang, China, May 2011, pp. 728-733.

Shu X., Heins W., Ballesteros P., Bohn C. 2013, Two-parameter pLPV modeling of nonstationary harmonically related multisine disturbances for reduced-order gain-scheduling control. Proc. of the 32nd IAESTED Int. Conf. on Model., Identif. and Control, Innsbruck, Austria, Feb. 2013, pp. 404-411.

Stilwell D., Rugh W. 1998, Interpolation of observer state feedback controllers for gain scheduling. Proc. of the Am. Control Conf., Philadelphia, USA, June 1998, vol. 2, pp. 1215-1219.

Takagi K., Saigo M. 2006, Vibration control of a smart structure with identification of a crack experimental verification of a gain-scheduled controller. Proc. of the SPIE Smart Struct. and Mater., San Diego, USA, Feb. 2006, pp. 61661A.1-61661A.12.

Tliba S., Varnier M. 2010, Dealing with actuator saturation for active vibration control of a flexible structure piezo-actuated [sic]. Proc. of the IEEE Int. Conf. on Control Appl., Yokohama, Japan, Sep. 2010, pp. $1743-1748$. 